Siberian Journal of Life Sciences and Agriculture, Vol 10, №5, 2018

DOI: 10.12731/wsd-2018-5-74-87

УДК 636.5:591.434

\title{
МОРФОМЕТРИЧЕСКАЯ \\ ХАРАКТЕРИСТИКА ТОЩЕЙ И ПОДВЗДОШНОЙ КИШКИ ЦЫПЛЯТ-БРОЙЛЕРОВ КРОССА РОСС 308 ЧЕРЕЗ 30 И 40 СУТОК ПОСТНАТАЛЬНОГО ПЕРИОДА В НОРМЕ И ПРИ ДОБАВЛЕНИИ В РАЦИОН ПОСЛЕСПИРТОВОЙ СУХОЙ БАРДЫ
}

Понкратова Т.Ю., Мелешков С.Ф., Сидорова Д.Г.

Цель. Провести сравнительный анализ морфометрических показателей стенки тощей и подвздошной кишки иььплят-бройлеров кросса РОСС 308 в возрасте 30 и 40 суток постнатального развития при использовании стандартного рациона и с добавлением сухой послеспиртовой барды.

Материалы и методы. В работе применены описательно-оценочные методы и морфометрический анализ. Достоверность различия переменных величин контрольной и экспериментальной групп определяли методом Манна-Уитни, также использовался дисперсионный анализ Краскелла-Уоллиса при помощи пакета прикладных программ Statistica for Windows (Версия 6.0, StatSoft, Inc.). Нами проведены исследования тощей и подвздошной кишки. Изучены длина ворсинок и крипт, высота эпителия ворсинок, количество бокаловидных клеток, ширину пластинок слизистой оболочки, иирину мышечной и серозных оболочек.

Результаты. Нами установлено, что морфологические изменения в строении подвздошной кишки при добавлении в рацион послеспиртовой сухой барды формировались уже через 30 суток постнатального онтогенеза что подтверждают и данные корреляиионного анализа. Изменения в морфологическом строении тощей кишки носят отсроченный характер и выявлялись только через 40 суток постнатального онтогенеза, проявляясь более высокими показателями по всем исследуемым параметрам. Эти результаты подтверждаются данными корреляционного анализа, свидетельствующие о наличии связи средней и высокой степени между рачионом питания и морфометрическими показателями тощей кишки.

Заключение. Таким образом, изменения в тощей кишке иьыплят-бройлеров в основной группе выражены при исследовании ширины собственной 
и мымечной пластинок слизистой оболочки. При исследовании подвздошной кишки были выражены изменения параметров иирины собственной и мышечной пластинок.

Ключевые слова: тощая; подвздошная; кишка; иыплята-бройлеры; морфология.

\section{MORPHOMETRIC CHARACTERISTICS OF THE DUODENUM OF BROILER CHICKENS ROSS 308 AFTER 30 AND 40 DAYS OF POSTNATAL ONTOGENESIS IN NORM AND WHEN YOU ADD IN THE DIET OF DRY GRAIN DISTILLERY STILLAGE}

\section{Ponkratova T.Yu., Meleshkov S.F., Sidorova D.G.}

Background. To conduct a comparative analysis of the morphometric indices of the skin of the lean and ileum of broiler chickens of RBS 308 at the age of 30-40 days of postnatal development with the use of a standard diet and with the addition of a dry post-alcohol bard.

Materials and methods. Descriptive-evaluation methods and morphometric analysis were applied in the work. The reliability of the difference in the variables between the control and experimental groups was determined by the Mann-Whitney method, and the Kruskell-Wallis variance analysis was also used with the Statistica for Windows application software package (Version 6.0, StatSoft, Inc.). We carried out studies of the jejunum and ileum. The length of the villi and crypts, the height of the villous epithelium, the number of goblet cells, the width of the mucosa plates, the width of the muscular and serous membranes were studied.

Results. We established that the morphological changes in the structure of the ileum with the addition of the post-alcohol dry bard to the diet were formed after 30 days of postnatal ontogenesis, which is confirmed by the data of the correlation analysis. Changes in the morphological structure of the jejunum are delayed and revealed only after 40 days of postnatal ontogenesis, manifesting themselves higher indices for all the parameters studied. These results are corroborated by the data of the correlation analysis, indicating the presence of a medium to high degree relationship between the diet and the morphometric parameters of the jejunum. 
Conclusion. Thus, changes in the jejunum of broiler chickens in the main group are expressed when examining the width of the own and muscular plates of the mucous membrane. In the study of the ileum, changes in the parameters of the width of the own and muscle plates were expressed.

Keywords: lean; ileum; gut; broiler chickens; morphology.

\section{Введение}

Птицеводство - одна из отраслей животноводства, обеспечивающая население высокоценными диетическими продуктами питания. При этом птицеводство продолжает испытывать дефицит дешевого и полноценного кормового белка [1, с. 43-44]. Зерновые корма являются основным источником энергии для птицы. Существенным резервом экономии зерна может стать максимальное увеличение в комбикормах незерновой части [2]. В России зерновые корма в рационах птицы составляют более $73 \%$, а незерновые компоненты в значительно меньших количествах. Одним из перспективных кормовых средств для использования в птицеводстве является послеспиртовая барда. Сухая послеспиртовая барда содержит все необходимые питательные вещества. По содержанию питательных веществ она близка к кормовым дрожжам и подсолнечным шротам [3, с. 146]. Проводимые нами исследования были направлены на изучение влияния сухой послеспиртовой барды на морфологию тонкого отдела кишечника цыплят-бройлеров РОСС 308 через 30 и 40 суток постнатального развития.

Для получения современных представлений о морфофункциональных особенностях пищеварительной системы и обоснования применения кормовых добавок и кормов на продуктивные качества птицы требуется изучение особенностей гистологического строения кишечника, характерных для каждого кросса.

Цель исследований: провести сравнительный анализ морфогистометрических показателей стенки тощей и подвздошной кишки цыплят-бройлеров кросса РОСС 308 в возрасте 30 и 40 суток постнатального развития при использовании стандартного рациона и с добавлением сухой послеспиртовой барды.

\section{Материалы и методы исследования}

Исследование проводилось в зимний период 2016 года на базе Института ветеринарной медицины и биотехнологии Федерального государственного бюджетного образовательного учреждения высшего образования Омского государственного аграрного университета имени П.А. Столы- 
пина, на цыплятах-бройлерах кросса РОСС 308. Было сформировано две группы цыплят-бройлеров: контрольная группа $(\mathrm{n}=5)$, в которой использовался основной рацион и опытная группа $(\mathrm{n}=5)$ с основным рационом с добавлением $3 \%$ сухой послеспиртовой барды через 30 и 40 суток постнатального периода. Цыплята содержались в одинаковых условиях на основном рационе [4]. Птица выводились из эксперимента путем декапитации, с учетом рекомендаций приложения №4 к правилам проведения работ с использованием экспериментальных животных [5].

У цыплят каждой группы были взяты тощая и подвздошная кишка. Материал фиксировался в 10\% нейтральном растворе формалина на фосфатном буфере фирмы ООО «Биовитрум», блоки заливали в парафин по общепринятой методике [6, с. 218-225]. На ротационном микротоме Labo Cat 4055 (фирма Slee, Германия) готовили срезы толщиной 3-5 мкм, которые окрашивали гематоксилином и эозином. При изготовлении гистопрепаратов использовалось сертифицированное лабораторное оборудование. Измерение гистологических структур производили при помощи окуляра с измерительной шкалой.

В работе применены описательно-оценочные методы и морфометрический анализ. Статистический анализ включал определение средней арифметической, нахождение стандартного отклонения. Достоверность различия переменных величин контрольной и экспериментальной групп определяли методом Манна-Уитни, также использовался дисперсионный анализ Краскелла-Уоллиса при помощи пакета прикладных программ Statistica for Windows (Версия 6.0, StatSoft, Inc.) с учетом рекомендаций О.Ю. Ребровой [7, с. 312].

\section{Результаты исследования и их обсуждение}

По данным К.А. Кулешова и другие авторы $[8$, с. 63, 9, 10] ворсинки на протяжении всей поверхности слизистой оболочки тонкого кишечника кур листовидной, зигзагообразной формы. По его данным длина ворсинок в тощей и подвздошной кишке 800 мкм. По данным наших исследований длина ворсинок тощей кишки в основной группе к 30 суткам составляла от 929,5 до 1058,2 мкм и не изменялась к 40 суткам, и значимо не отличалась от контрольной группы ( $\mathrm{p}=0,12)$. При изучении длины ворсинок подвздошной кишки в основной группе на 30 сутки она колебалась от 514,8 до 614,9 мкм, значительно не отличалась от контрольной группы (p=0,17), а через 40 суток длина ворсинок в контрольной группе уменьшалась на $20,9 \%(\mathrm{p}=0,92)$, а в основной группе на $9,5 \%(\mathrm{p}=0,000001)$ и составляла от 
486,2 до 557,7 мкм, показывая увеличение показателя контрольной группы на $11,8 \%(\mathrm{p}=0,000022)$.

К.А. Кулешов [8, с. 63] так же отмечает, что у основания ворсинок открываются общекишечные железы (крипты). Они простые, трубчатого строения. Размеры крипт повышаются с возрастом кур, например, у 56 суточной птицы длина крипт составляет 80-150 мкм, а у 180 суточных 60-180 мкм, и прямо пропорционально возрасту птицы увеличивается и глубина крипт. Нами установлено, что длина крипт в тощей кишке на 30 сутки постнатального развития в основной группе составляла 52,8-118,8 мкм, к 40 суткам 105,6-167,2 мкм увеличилась на $81,1 \%(\mathrm{p}=0,000001)$ и на $5,6 \%$ превышала показатель контрольной группы $(\mathrm{p}=0,012)$. Длина крипт подвздошной кишки в основной группе составляла от 70,4 до 200,2 мкм и значимо не изменялась на протяжении исследования, но превышала показатель контрольной группы через 30 и 40 суток постнатального периода на $62,5(\mathrm{p}=0,000001)$ и $44,4 \%(\mathrm{p}=0,045)$ соответственно.

О.В. Волкова и другие авторы $[11$, с. $187,10,12,13]$ отмечают, что эпителий, выстилающий кишечные ворсинки содержит каемчатые энтероциты. Это высокие цилиндрические клетки с умеренно развитыми органеллами. На своей верхушке содержат до 3 тысяч микроворсинок. Энтероциты выполняют важную функцию всасывания, пристеночного пищеварения и препятствия проникновения микроорганизмов вовнутрь клетки. По нашим данным высота эпителия на вершине ворсинок тощей кишки в основной группе в исследуемые периоды была 26,4-39,6 мкм, но к 40 суткам увеличилась на $16,7 \%$ в сравнении с контрольной группой $(\mathrm{p}=0,022)$. Высота эпителия у основания ворсинок в тощей кишке колебалась от 17,6 до 35,2 мкм, на 20\% превышая высоту эпителия контрольной группы ( $\mathrm{p}=0,0012)$. В подвздошной кишке высота эпителия на вершине ворсинки составляла 26,4-35,2 мкм, в контрольной и основной группах в исследуемые периоды статистически не отличалась. У основания ворсинки в основной группе высота эпителия не изменялась, в контрольной группе через 30 и 40 суток постнатального периода произошло увеличение на $14,3(\mathrm{p}=0,0031)$ и $33,3 \%$ ( $\mathrm{p}=0,000001)$ соответственно.

По данным В.Г. Елисеева и др. [14, с. 477, 15] бокаловидные клетки это клетки эпителия, накапливающие и выделяющие большое количество слизи, увлажняющей поверхность эпителия. Количество бокаловидных клеток в тощей кишке на 1 мм длины ворсинки в основной группе составляло 21-45 клеток и не изменялось на протяжении периода исследования, в контрольной группе через 40 суток постнатального периода увеличи- 
валось в 2,4 раза ( $\mathrm{p}=0,000001)$. В подвздошной кишке в основной группе через 30 суток постнатального периода количество бокаловидных клеток ворсинки на 1 мм длины составляло 18-35 клеток, что больше на 2,2\% чем в контрольной группе $(\mathrm{p}=0,0037)$. К 40 суткам в контрольной и основной группах произошло увеличение количества бокаловидных клеток. В основной группе на 69,6 (p=0,000001), в контрольной на $68,9 \%$ ( $\mathrm{p}=0,000001)$, статистически значимых отличий между ними не выявлялось.

Под эпителием располагается собственная пластинка слизистой оболочки, образованная рыхлой соединительной тканью с большим количеством клеточных элементов (фибробласты, гистиоциты, лимфоциты, плазмоциты). Мышечная пластинка представлена продольным слоем миоцитов [16, с. 46-47]. По результатам наших исследований ширина собственной пластинки слизистой оболочки тощей кишки у цыплят-бройлеров через 30 суток постнатального развития составляла 35,2-44 мкм, значимо не отличаясь от показателя контрольной группы $(\mathrm{p}=0,14)$, а к 40 суткам ее ширина в контрольной группе уменьшалась на $66,7 \%(\mathrm{p}=0,000001)$, а в основной группе уменьшалась на $55,6 \%(\mathrm{p}=0,000001)$, составляя от 13,2 до 26,4 мкм и на $33,3 \%$ была больше аналогичного показателя контрольной группы ( $\mathrm{p}=0,00001)$. Ширина мышечной пластинки тощей кишки на 30 сутки постнатального периода в основной и контрольной группах не отличалась и составляла $8,8-17,6$ мкм. Через 40 суток в контрольной группе она снижалась на $33,3 \%(\mathrm{p}=0,000001)$, а в основной группе увеличилась на $66,7 \%(\mathrm{p}=0,000001)$ и в 2,5 раза превышала аналогичный показатель контрольной группы ( $=0,000001)$. Ширина собственной пластинки слизистой оболочки подвздошной кишки на 30 сутки в основной группе составляла 105,6-123,2 мкм, превышая аналогичный показатель контрольной группы в 4,5 раза ( $\mathrm{p}=0,000001)$. К 40 суткам постнатального периода ширина собственной пластинки в контрольной группе уменьшалась на $33,3 \%(\mathrm{p}=0,000001)$, а основной группе на $37 \%(\mathrm{p}=0,000084)$, составляла $35,2-123,2$ мкм и в 4,25 раза превышала показатель контрольной группы $(\mathrm{p}=0,000001)$. Ширина мышечной пластинки слизистой оболочки подвздошной кишки в исследуемые периоды в основной группе составляла 13,2-35,2 мкм, превышая показатель контрольной группы на 30 сутки в 1,5 раза $(\mathrm{p}=0,000001)$ и на 40 сутки в 3 раза $(\mathrm{p}=0,000001)$.

По мнению многих авторов $[17,18,19,20]$ подслизистая основа кишечника образована рыхлой соединительной тканью. Мышечная оболочка состоит из миоцитов, расположенных во внутреннем слое циркулярно, а в наружном - продольно. По данным наших исследований толщина цир- 
кулярного мышечного слоя преобладает над продольным во всех участках тонкого кишечника. Серозная оболочка во все возрастные периоды у цыплят-бройлеров относительно не широкая, она представлена рыхлой соединительной тканью, покрытой мезотелием. Толщина мышечной оболочки тощей кишки через 30 суток постнатального периода в основной группе составляла 132-198 мкм и статистически значимо не отличалась от показателей контрольной группы. Через 40 суток в контрольной группе толщина мышечной оболочки увеличилась на $20,5 \%$ ( $\mathrm{p}=0,000001)$, а в основной группе на $62,8 \%(\mathrm{p}=0,000001)$, составляла 202,4-352 мкм и на $40 \%$ превышала показатель контрольной группы ( $\mathrm{p}=0,000001)$. Толщина мышечной оболочки подвздошной кишки в основной группе через 30 суток постнатального периода составляла от 264 до 396,6 мкм, что на 27,3\% меньше чем показатель контрольной группы. К 40 суткам толщина ее в контрольной группе снижалась на $41,8 \%(\mathrm{p}=0,000001)$, а в основной - на $15 \%(\mathrm{p}=0,0019)$ и на $6,25 \%$ превышала показатель контрольной группы $(\mathrm{p}=0,026)$. Толщина серозной оболочки тощей кишки на 30 сутки постнатального онтогенеза составляла 13,2-17,6 мкм как в основной так и в контрольной группах. К 40 суткам ее толщина в контрольной группе снижалась на $33,3 \%$ ( $=0,000001)$, в основной группе увеличивалась на $33,3 \%$ и составляла $8,8-26,4$ мкм и в 2 раза превышала показатель контрольной группы $(\mathrm{p}=0,00086)$. Толщина серозной оболочки подвздошной кишки в основной группе составляла 13,2-17,6 мкм и не изменялась на протяжении исследуемого периода, а показатель контрольной группы к 40 суткам постнатального периода увеличивался на $50 \%$ ( $=0,000001)$.

Таким образом, морфологические изменения в строении подвздошной кишки при добавлении в рацион послеспиртовой сухой барды формировались уже через 30 суток постнатального онтогенеза что подтверждают и данные корреляционного анализа (таблица 1).

Таблицуа 1.

Результаты корреляционного анализа морфометрических показателей тощей кишки с рационом питания (указаны значения коэффициента корреляции $\mathrm{G}$ при $\mathbf{p}<0,05)$

\begin{tabular}{|l|c|c|}
\hline Показатель & 30 сутки & 40 сутки \\
\hline Высота ворсинки, мкм & 0,33 & 0,41 \\
\hline Длина крипт, мкм & - & 0,48 \\
\hline Высота эпителия на вершине ворсинки, мкм & - & 0,48 \\
\hline Высота эпителия у основания ворсинки, мкм & 0,70 & 0,73 \\
\hline
\end{tabular}


Окончание табл. 1.

\begin{tabular}{|l|c|c|}
\hline Ширина собственной пластинки слизистой оболочки, мкм & 0,33 & 0,89 \\
\hline Ширина мышечной пластинки слизистой оболочки, мкм & 1,0 & 1,0 \\
\hline Толщина мышечной оболочки, мкм & - & 0,73 \\
\hline Толщина серозной оболочки, мкм & 0,43 & 0,69 \\
\hline Количество бокаловидных клеток на 1 мм длины & - & 1,0 \\
\hline
\end{tabular}

Изменения в морфологическом строении тощей кишки носят отсроченный характер и выявлялись только через 40 суток постнатального онтогенеза, проявляясь более высокими показателями по всем исследуемым параметрам. Эти результаты подтверждаются данными корреляционного анализа, свидетельствующие о наличии связи средней и высокой степени между рационом питания и морфометрическими показателями тощей кишки (таблица 2).

Таблицуа 2.

Результаты корреляционного анализа морфометрических показателей подвздошной кишки с рационом питания (указаны значения коэффициента корреляции G при р<0,05)

\begin{tabular}{|l|c|c|}
\hline Показатель & 30 сутки & 40 сутки \\
\hline Высота ворсинки, мкм & - & 0,76 \\
\hline Длина крипт, мкм & 0,88 & 0,37 \\
\hline Высота эпителия на вершине ворсинки, мкм & 0,78 & - \\
\hline Высота эпителия у основания ворсинки, мкм & 0,50 & 0,96 \\
\hline Ширина собственной пластинки слизистой оболочки, мкм & 1,0 & 1,0 \\
\hline Ширина мышечной пластинки слизистой оболочки, мкм & 1,0 & 1,0 \\
\hline Толщина мышечной оболочки, мкм & 0,99 & 0,45 \\
\hline Толщина серозной оболочки, мкм & - & 0,81 \\
\hline Количество бокаловидных клеток на 1 мм длины & 0,48 & - \\
\hline
\end{tabular}

\section{Заключение}

1. Длина ворсинок подвздошной кишки через 40 суток постнатального периода в контрольной группе уменьшалось на $20,9 \%$, а в основной группе на 9,5\%. Длина ворсинок тощей кишки значительных отличий во всех периодах исследования не имеет.

2. Длина крипт тощей кишки к 40 суткам постнатального онтогенеза в основной группе увеличивался на $81,1 \%$ и на $5,6 \%$ в контрольной группе. В подвздошной кишке показатель основной группы превышает показатель контрольной группы через 30 суток на 62,5\%, а через 40 суток на $44,4 \%$. 
3. Высота эпителия на верхушке ворсинки тощей кишки в основной группе к 40 суткам увеличивалась на $16,7 \%$, у основания ворсинок в основной группе была выше на $20 \%$ чем в контрольной группе. В подвздошной кишке у основания ворсинок в контрольной группе произошло увеличение через 30 суток на 14,3\%, через 40 суток на $33,3 \%$.

4. Количество бокаловидных клеток на 1 мм длины ворсинки тощей кишки в контрольной группе к 40 суткам увеличивалось в 2,4 раза. В подвздошной кишке в основной группе на 30 сутки на 2,2\% больше чем в контрольной группе, к 40 суткам произошло увеличение в контрольной группе на $68,9 \%$, в основной группе на $69,6 \%$.

5. Ширина собственной пластинки тощей кишки к 40 суткам уменьшалось в контрольной группе на 66,7\%, в основной на 55,6\%. Мышечная пластинка к 40 суткам в контрольной группе ее ширина уменьшалась на $33,3 \%$, а в основной группе увеличивалась на $66,7 \%$. Ширина собственной пластинки подвздошной кишки на 30 сутки в основной группе в 4,5 раза превышала показатель контрольной группы, к 40 суткам произошло уменьшение в контрольной группе на $33,3 \%$, а в основной группе на $37 \%$, что в 4,25 раза превышала показатель контрольной группы.

6. Толщина мышечной оболочки тощей кишки через 40 суток в контрольной группе увеличивалось на $20,5 \%$, а в основной группе на $62,8 \%$. Толщина мышечной оболочки подвздошной кишки на 30 сутки в основной группе меньше на 27,3\% чем в контрольной группе. К 40 суткам толщина в контрольной группе уменьшалась на $41,8 \%$, а в основной группе на $15 \%$.

7. Добавление в рацион послеспиртовой сухой барды особенно выраженное влияние оказывает на ширину собственной и мышечной пластинок слизистой оболочки, как в тощей, так и в подвздошной кишке.

\section{Список литературы}

1. Улитько В.Е. Рост, убойные и мясные качества бройлеров при использовании в рационе БВМД на основе сухой спиртовой барды / В.Е. Улитько, О.Е. Ерисанова // Вестник УГСХА. 2010. №1(11). С. 43-44.

2. Lilian FA de Souza, Denise N. Araujo, Lenita M. Stefani, Ines C. Giometti, Valguiria C. Cruz-Polycarpo, Gustavo Polycarpo, Maria F. Burbarelli. Probiotics on performance, intestinal morphology and carcass characteristics of broiler chickens raised with lower or higher environmental challenge // Austral journal of veterinary sciences. 2018, vol. 50, no.1, pp. 1025-1036. 
3. Егорова Т.А. Повышение питательной ценности послеспиртовой барды / T.A. Егорова и др. // Материалы XVIII Международной конференции ВНАП - 2015. С. 146.

4. ГОСТ 18221-99. Комбикорма полнорационные для сельскохозяйственной птицы. Технические условия. - взамен ГОСТ 18221-72; Введ. С 01.07.2002. Москва: Изд-во стандартов, 2002. 10 с.

5. Приказ Минздрава СССР «О мерах по дальнейшему совершенствованию организационных форм работы с использованием экспериментальных животных», от 12.08.1977 №755.

6. Семченко В.В. Морфологические методы исследования в ветеринарной медицине: учебное пособие / Семченко В.В., Барашкова С.А., Хонин Г.А. Омск: Обл. типография, 2004. С. 218-225.

7. Реброва О.Ю. Статистический анализ медицинских данных. Применение пакета прикладных программ STATISTICA. М.: МедиаСфера. 2000. 312c.

8. Кулешов К.А. Постнатальный морфогенез органов желудочно-кишечного тракта кур при применении селенсодержащих препаратов // Ветеринарная патология. 2010. №1. С. 63.

9. Харитоник Д.Н. Морфоструктурные особенности тонкого кишечника цыплят-бройлеров кросса «Кобб» под влиянием «Катозала» / Д.Н. Харитоник, Г.А. Тумилович // Актуальные проблемы интенсивного развития животноводства. 2012. № 2. С. 288-295.

10. Матвеев О.А. Морфометрические показатели органов пищеварения цыплят-бройлеров кросса Ross 308 / O.А. Матвеев, М.М. Жамбулов // Известия Оренбургского государственного аграрного университета. 2017. № 4. C. $119-122$.

11. Волкова О.В. Основы гистологии и гистологической техники. Учебник / Волкова О.В., Елецкий Ю.К. М.: Медицина, 1982. С. 187.

12. H. de Verdal, S. Mignon-Grasteau, C. Jeulin, E. Le Bihan-Duval. Digestive tract measurements and histological adaptation in broiler lines divergently selected for digestive efficiency // Poultry Science, 2010, vol. 89, issue 9, pp. 1955-1961.

13. L. Esmailzadeh, M. Shivazad, AA. Sadeghi, M. Karimitorshizi. Performance, Intestinal Morphology and Microbiology of Broiler Chickens Fed Egg Powder in the Starter Diet // Brazilian journal of Poultry Science. 2016, vol. 18, no. 4, pp. 856-863.

14. Елисеев В.Г. Гистология / Елисеев В.Г. и др. М., 1972. С. 477.

15. Просекова Е.А. Распределение и возрастная динамика бокаловидных клеток в кишечнике цыплят-бройлеров // Материалы Международной научной конференции молодых учёных и специалистов, посвящ. 140-летию РГАУ-МСХА имени К.А. Тимирязева. М., 2006. С. 603-606. 
16. Сайко С.Г. Морфология желудочно-кишечного тракта домашней утки / Сайко С.Г., Рабовская Л.А. // Аграрный вестник Урала. 2010. №11-2(77). С. 46- 47.

17. Пономарева Т.А. Сравнительно-возрастная морфология кишечника и его кровоснабжение у домашних уток и кур. Автореферат. Екатеринбург, 2004. C. 18.

18. Грозина А.А. Морфологическая оценка стенки кишечника цыплят кросса «Кобб 500» на фоне применения антибиотика и пробиотика / А.А. Грозина, В.В. Пронин, М.С. Дюмин // Российский ветеринарный журнал. Сельскохозяйственные животные, 2014. №4. С. 16-17.

19. Nabizadeh A. The effect of inulin on broiler chicken intestinal microflora, gut morphology, and performance // Journal of Animal and Feed Sciences, 2012, vol. 21 , no. 21 (4), pp. 725-734.

20. Chen G.Olnooda, Sleman S.M.Beski, Paul A. Ijia, Mingan Choct. Delivery routes for probiotics: Effects on broiler performance, intestinal morphology and gut microflora // Animal Nutrition. 2015, vol. 1, issue 3, pp. 192-202.

\section{References}

1. Ulit'ko V.E., Yerisanova O.E. Vestnik UGSKhA [Bulletin of the UGSA]. 2010. №1 (11), pp. 43-44.

2. Lilian FA de Souza, Denise N. Araujo, Lenita M. Stefani, Ines C. Giometti, Valguiria C. Cruz-Polycarpo, Gustavo Polycarpo, Maria F. Burbarelli. The Australian Journal of Veterinary Sciences. 2018, vol. 50, no.1, pp. 1025-1036.

3. Egorova T.A. et al. Povyshenie pitatel'noy tsennosti poslespirtovoy bardy [Nutritional value of the distillery stillage]. Materialy XVIII Mezhdunarodnoy konferentsii VNAP - 2015 [Proceedings of the XVIII International Conference of the GNAP - 2015]. P. 146.

4. GOST 18221-99. Complete feed for poultry. Technical conditions. instead of GOST 18221-72; Enter From 01.07.2002. Moscow: Standards Publishing House, 2002. $10 \mathrm{p}$.

5. Order of the Ministry of Health of the USSR "On measures to further improve the organizational forms of work with the use of experimental animals", dated 12.08.1977 №755.

6. Semchenko V.V., Barashkova S.A., Khonin G.A. Morfologicheskie metody issledovaniya $v$ veterinarnoy meditsine [Morphological research methods in veterinary medicine]. Omsk: Obl. printing house, 2004, pp. 218-225.

7. Rebrova O.Yu. Statisticheskiy analiz meditsinskikh dannykh. Primenenie paketa prikladnykh programm STATISTICA [Statistical analysis of medical data. Application software package STATISTICA]. M.: MediaSfera. 2000. 312 p. 
8. Kuleshov K.A. Postnatal'nyy morfogenez organov zheludochno-kishechnogo trakta kur pri primenenii selensoderzhashchikh preparatov [Postnatal morphogenesis of the organs of the gastrointestinal tract of chickens when using selenium-containing preparations]. Veterinarnaya patologiya [Veterinary Pathology]. 2010. №1. P. 63.

9. Kharitonik D.N., Tumilovich G.A. Morfostrukturnye osobennosti tonkogo kishechnika tsyplyat-broylerov krossa «Kobb» pod vliyaniem «Katozala» [Morphostructural features of the small intestine of broiler chickens of the Cobb cross under the influence of Katozala]. Aktual'nye problemy intensivnogo razvitiya zhivotnovodstva [Actual problems of intensive development of animal husbandry]. 2012. № 2, pp. 288-295.

10. Matveev O.A., Zhambulov M.M. Morfometricheskie pokazateli organov pishchevareniya tsyplyat-broylerov krossa Ross 308 [Morphometric indices of the digestive organs of broiler chickens of the cross Ross 308]. Izvestiya Orenburgskogo gosudarstvennogo agrarnogo universiteta [News of the Orenburg State Agrarian University]. 2017. No. 4, pp. 119-122.

11. Volkova O.V., Eletsky Yu.K. Osnovy gistologii i gistologicheskoy tekhniki [Fundamentals of histology and histological techniques]. Medicine, 1982. P. 187.

12. H. de Verdal, S. Mignon-Grasteau, C. Jeulin, E. Le Bihan-Duval. Digestive tract measurements in broiler lines and divergently selected for digestive efficiency. Poultry Science, 2010, vol. 89, issue 9, pp. 1955-1961.

13. L. Esmailzadeh, M. Shivazad, AA. Sadeghi, M. Karimitorshizi. Performance, Intestinal Morphology and Microbiology of the Broiler Chickens Fed Egg Powder in the Starter Diet. Brazilian journal of Poultry Science. 2016, vol. 18, no. 4, pp. 856-863.

14. Eliseev V.G. et al. Gistologiya [Histology]. M., 1972. P. 477.

15. Prosekova E.A. Raspredelenie i vozrastnaya dinamika bokalovidnykh kletok v kishechnike tsyplyat-broylerov [Distribution and age dynamics of goblet cells in the intestines of broiler chickens]. Materialy Mezhdunarodnoy nauchnoy konferentsii molodykh uchenykh i spetsialistov, posvyashch. 140-letiyu RGAUMSKhA imeni K.A. Timiryazeva [Materials of the International Scientific Conference of Young Scientists and Specialists, dedicated. 140th anniversary of the Russian State Agrarian University-Moscow Agricultural Academy named after K.A. Timiryazev]. M., 2006, pp. 603-606.

16. Sayko S.G., Rabovskaya L.A. Morfologiya zheludochno-kishechnogo trakta domashney utki [The morphology of the gastrointestinal tract of domestic ducks]. Agrarnyy vestnik Urala [Agrarian Bulletin of the Urals]. 2010. №11-2 (77), pp. $46-47$. 
17. Ponomareva T.A. Sravnitel'no-vozrastnaya morfologiya kishechnika i ego krovosnabzhenie u domashnikh utok $i$ kur [Age-related intestinal morphology and its blood supply in domestic ducks and chickens]. Abstract. Yekaterinburg, 2004, pp. 18.

18. Grozina A.A., Pronin V.V., Dyumin M.S. Morfologicheskaya otsenka stenki kishechnika tsyplyat krossa «Kobb 500» na fone primeneniya antibiotika i probiotika [Morphological assessment of the intestinal wall of the Cobb 500 cross-breeding chickens on the background of the use of antibiotic and probiotic]. Rossiyskiy veterinarnyy zhurnal. Sel'skokhozyaystvennye zhivotnye [Russian Veterinary Journal. Farm animals], 2014. №4, pp. 16-17.

19. Nabizadeh A. The effect of intestinal microflora, gut morphology, and performance. Journal of Animal and Feed Sciences, 2012, vol. 21, no. 21 (4), pp. 725-734.

21. Chen G. Olnooda, Sleman S.M. Beski, Paul A. Ijia, Mingan Choct. Delivery routes for probiotics: Effects on broiler performance, intestinal morphology and gut microflora. Animal Nutrition. 2015, vol. 1, issue 3, pp. 192-202.

\section{ДАННЫЕ ОБ АВТОРАХ}

\section{Понкратова Татьяна Юрьевна, специалист}

ФГБОУ ВО Омский государственный медицинский университет Министерства здравоохранения Российской Федераџии ул. Ленина, 12, г. Омск, 644099, Российская Федерация tanya558855@mail.ru

Мелешков Сергей Федорович, д-р ветеринар. наук, профессор ФГБОУ ВО Омский ГАУ

Институтская площуадь, 1, г. Омск, 644008, Российская Федерация sf.meleshkov@omgau.org

Сидорова Дарья Геннадьевна, канд. биол. наук, доцент ФГБОУ ВО Омский ГАУ Институтская площадь, 1, г. Омск, 644008, Российская Федеращия dg.sidorova@omgau.org

\section{DATA ABOUT THE AUTHORS}

Ponkratova Tatiana Yurievna, Specialist

Omsk State Medical University

12, Lenin Str., Omsk, 644099, Russian Federation tanya558855@mail.ru 
Meleshkov Sergey Fyodorovich, Dr. of vet. Sciences, Professor Omsk State Agrarian University

1, Institutskaya square, Omsk, 644008, Russian Federation sf.meleshkov@omgau.org

Sidorova Daria Gennadievna, Cand. Biol. Sciences, Associate Professor Omsk State Agrarian University

1, Institutskaya square, Omsk, 644008, Russian Federation dg.sidorova@omgau.org 